\title{
Development of User-Friendly Software to Design Dairy Heat Exchanger and Performance Evaluation
}

\author{
DipankarMandal*
}

*Faculty of Agricultural Engineering, Bidhan Chandra KrishiViswavidyalaya,Mohanpur, Nadia, West Bengal, India, Pin-741252.

\section{ABSTRACT}

The paper proposes a calculation algorithm and development of a software in Visual Basic(Visual Studio 2012 Express Desktop) used in heat transfer studies when different heat exchangers are involved (e.g. Helical Type Triple Tube Heat Exchanger, Plate Type Heat Exchanger).It includes the easy calculation of heat transfer coefficient and followed by the design and simulation of heat exchanger design parameter by inputting general known parameters of a heat exchanger into the developed software-_-DAIRY -HE ". A parametric study is conducted using the software interface to determine the length of tubes or dimensions of heat exchanger.

Keywords-Heat Exchanger, Triple Tube Concentric Helical Heat Exchanger, Double Tube Concentric Helical Heat Exchanger, Plate Type Heat Exchanger, Algorithm.

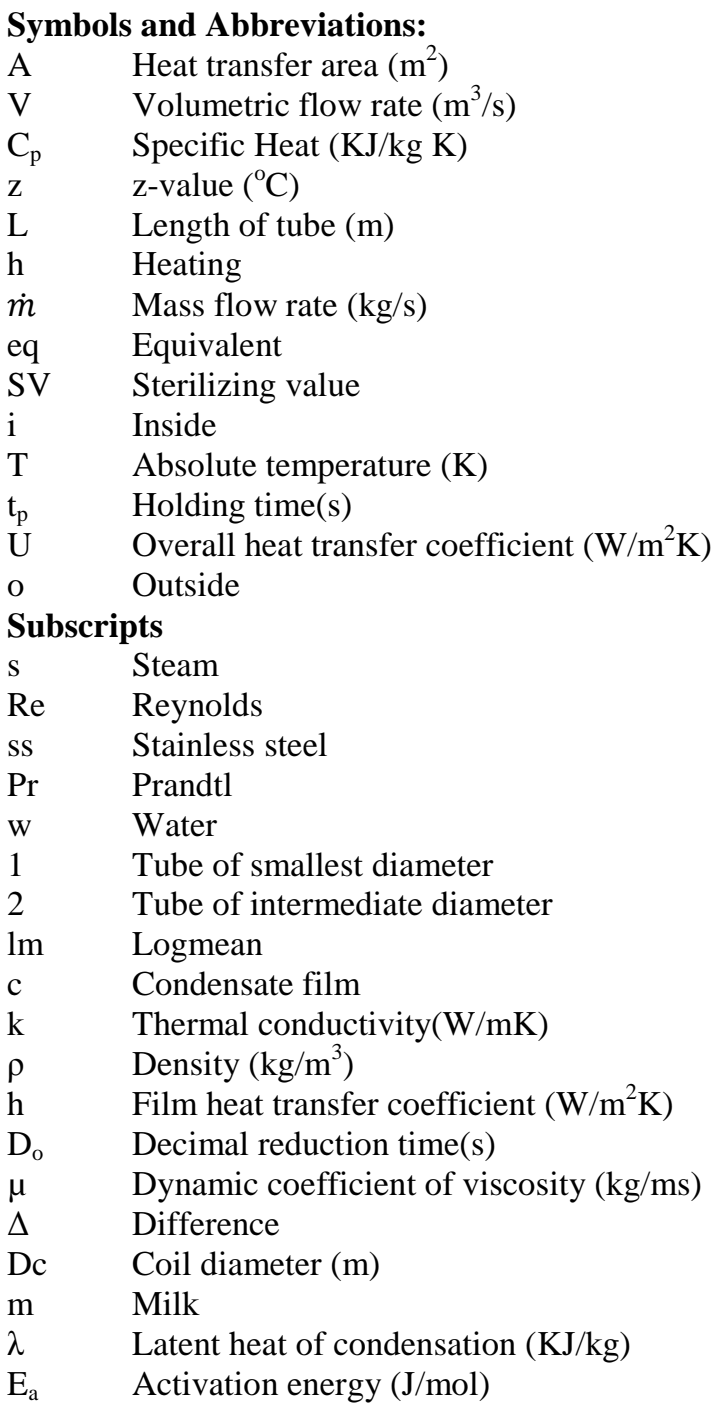

\section{Introduction}

Triple concentric type heat exchanger or plate types are frequently used in heat processes, coolingprocesses, pasteurization or sterilization applied in the dairy industry.Forthis type of heat exchanger different papers have developed case studies for the design and indirect testing of a heat exchanger and mathematical models have been developed and a numerical simulation has been made to observe the thermal and fluid dynamic behavior by Garcia-Valladres, 2004. And a computer based interactive solution for accurate estimation of heat transfer co-efficient in a helical tube heat exchanger by Sahoo et.al, 2003. And, the algorithm for design and performance evaluation of an indirect type helical tube UHT milk sterilizer also given by Sahoo et.al. And numerical and experimental studies of a double pipe helical heat exchanger is done by Romie,2004.From this literature review we have the idea about the heat transfer phenomena in the heat exchanger of different type.

\section{Design consideration}

In heating section the milk flows in the annular portion of triple tube and the heating medium (i.e. steam) flows in the inner most and outer most annulus. The holding section is a straight single tube for holding the process fluid. The cooling section the milk is cooled by flowed it in inner tube and cooling water at annular section of the tubes.

2.1.1. Heating section Design: The overall heat transfer coefficients are obtained from the following equations based on conduction and convection in cylindrical coordinates:

$U_{o 1}=\left(\frac{1}{h_{m}}+\frac{D_{o 1} \ln \left(D_{o 1} / D_{i 1}\right)}{2 k_{S S}}+\frac{D_{o 1}}{h_{c 1} D_{i 1}}\right)^{-1}$ 
$U_{i 2}=\left(\frac{1}{h_{m}}+\frac{D_{i 2} \ln \left(\left(D_{o 2} / D_{i 2}\right)\right.}{2 k_{S S}}+\frac{D_{i 2}}{h_{c 2} D_{o 2}}\right)^{-1}$

The condensate heat transfer coefficients can be obtained from the following equation (Kern, 1984):

$$
\begin{aligned}
& h_{c 1}=0.5754\left[\frac{k_{c}^{3} \rho_{c}^{2} g \lambda}{\mu_{c} D_{i l}\left(T_{s}-T_{\text {ilwall }}\right)}\right]^{0.25} \\
& h_{c 2}=\left[\frac{k_{c}^{3} \rho_{c}^{2} g \lambda}{\mu_{c} D_{o 2}\left(T_{s}-T_{\text {o2wall }}\right)}\right]^{0.25}
\end{aligned}
$$

Both the equation are obtained on the assumption that the flow of the condensate is laminar,i.e. $2 \tau_{c} / \mu_{c}<1.2$ $\mathrm{X} 10^{3}$ and $\mathrm{k}_{\mathrm{c}}, \rho_{\mathrm{c}}$ and $\mu_{\mathrm{c}}$ are estimated at film temperature.

$T_{f 1}=T_{s}-0.75\left(T_{s}-T_{\text {ilwall }}\right)$

$T_{f 2}=T_{s}-0.75\left(T_{s}-T_{o 2 w a l l}\right)$

Based on the principle of heat flux equivalence, the wall temperature can be shown as:

$\frac{T_{s}-T_{o 2 w a l l}}{1 / h_{c 2} D_{o 2}}=\frac{T_{o 2 w a l l}-T_{b m}}{\frac{\ln \left(D_{o 2} / D_{i 2}\right)}{2 k_{s s}}+\frac{1}{h_{m} D_{i 2}}}(7)$

2.1. Triple Tube Straight type heat exchanger: It consists of 3 sections namely-Heating Section, Holding section and Cooling Section.

$\frac{T_{s}-T_{i l w a l l}}{1 / h_{c 1} D_{i 1}}=\frac{T_{i l w a l l}-T_{b m}}{\frac{\ln \left[\left(D_{o} / D_{i 1}\right)\right.}{2 k_{S S}}+\frac{1}{h_{m} D_{o 1}}}(8)$

The milk side heat transfer coefficient for turbulent flow inside a tube can be estimated by the following equation (Geankoplis, 1997):

$h_{m}=\left(\frac{k_{m}}{D_{e q}}\right) 0.027 N_{R e}^{0.8} N_{P r}^{0.33}\left(\mu_{b} / \mu_{\text {wall }}\right)^{0.14}$

Since milk flows in the annular region of the tubes, the above equation can be modified, replacing $\left(\mu_{b} / \mu_{\text {wall }}\right)^{0.14}$ by $\left(D_{i 2} / D_{o 1}\right)^{0.53}$ (Zuritz, 1990).

The heat transfer coefficient for the helical tube heat exchanger is obtained by multiplying

$\left[1+3.5\left(D_{\text {eq }} / D_{c}\right)\right]$ withheat transfer coefficient of straight tube heat exchanger (Chopey\& Hicks, 1984). So, the final expression to evaluate the milk side heat transfer coefficient for turbulent flow in the annular region of the helical triple tube is given by:

$$
\begin{aligned}
h_{m}=\left(\frac{k_{m}}{D_{e q}}\right) & 0.027 N_{R e}^{0.8} N_{P r}^{0.33}\left(\mu_{b} / \mu_{\text {wall }}\right)^{0.14} \\
\times & {\left[1+3.5\left(D_{e q} / D_{c}\right)\right] }
\end{aligned}
$$

The heat exchanger length can be calculated from the heat balance equation,

$$
\begin{aligned}
& \dot{m}_{m} C_{m} \Delta T_{m}=\left(U_{o 1} A_{o 1}+U_{i 2} A_{i 2}\right) \Delta T_{l m} \\
& =\left(U_{o 1} \pi D_{o 1}+U_{i 2} \pi D_{i 2}\right) L \Delta T_{l m}
\end{aligned}
$$

2.1.2. Holding Section Design: The average velocity of milk through the holding tube can be obtained from, $v=\frac{\dot{V}}{A}$

The maximum velocity of milk can be obtained from $v_{\max }=\frac{v}{\left[0.0336\left(\log N_{R e}\right)+0.662\right]}$

$\left(\right.$ For $N_{R e}>2100$ (Toledo, 1991)).

And $\mathrm{D}$ value at any temperature $\mathrm{T}$ for a specified micro-organism can be estimated from Arrhenius equation,

$D_{T}=D_{o} \exp \left(\frac{E_{a}}{R}\left[\frac{1}{T}-\frac{1}{T_{o}}\right]\right)$

$\frac{E_{a}}{R}=\frac{\ln (10) T T_{0}}{z}$

The holding time of process fluid (milk) in holding tube can be estimated as follows:

$t_{p}=S V \times D_{T}$

The length of the holding tube can be obtained from:

$L=t_{p} v_{\max }$

\subsubsection{Cooling Section Design:}

The overall heat transfer coefficient can be obtained from

$U_{i 1}=\left(\frac{1}{h_{m}}+\frac{D_{i 1}^{\prime} \ln \left(D_{o 1}^{\prime} / D_{i 1}^{\prime}\right)}{2 k_{S S}}+\frac{D_{i 1}^{\prime}}{h_{w} D_{o 1}^{\prime}}\right)^{-1}$

Water and milk side heat transfer coefficient are estimated by -

$$
\begin{gathered}
h_{w}=\left(\frac{k_{m}}{D_{i 1}^{\prime}}\right) 0.027 N_{R e}^{0.8} N_{P r}^{0.33} \\
\left(\frac{\mu_{b}}{\mu_{\text {wall }}}\right)^{0.14}\left[1+3.5\left(D_{i 1}^{\prime} / D_{c}^{\prime}\right)\right] \\
h_{w}=\left(\frac{k_{w}}{D_{e q}^{\prime}}\right) 0.027 N_{R e}^{0.8} N_{P r}^{0.33}\left(D_{i 2}^{\prime} / D_{o 1}^{\prime}\right)^{0.53}[1 \\
\left.+3.5\left(D_{e q}^{\prime} / D_{c}^{\prime}\right)\right]
\end{gathered}
$$

By employing the heat flux equivalence concept, the wall temperature can be estimated as follows:

$$
\begin{aligned}
& \frac{T_{b m}-T_{i 1 \text { wall }}}{1 / D_{i 1}^{\prime} h_{m}}=\frac{T_{i 1 \text { wall }}-T_{b w}}{\frac{\ln \left(D_{o 1}^{\prime} / D_{i 1}^{\prime}\right)}{2 k_{s s}}+\frac{1}{h_{w} D_{o 1}^{\prime}}} \\
& \frac{T_{b m}-T_{o 1 w a l l}}{1 / D_{o 1}^{\prime} h_{w}}=\frac{T_{o 1 \text { wall }}-T_{b m}}{\frac{\ln \left(D_{o 1}^{\prime} / D_{i 1}^{\prime}\right)}{2 k_{s s}}+\frac{1}{h_{m} D_{i 1}^{\prime}}}
\end{aligned}
$$

The length of the cooling section can be obtained from the heat balance equation:

$m_{m} C_{m} \Delta T_{m}=\dot{m}_{w} C_{w} \Delta T_{w}$

$=U_{i 1} A_{i 1} \Delta T_{l m}=\pi L U_{i 1} D_{i 1}^{\prime} \Delta T_{l m}$

\subsection{Plate Type Heat Exchanger,}

For plate heat exchanger we have to choose flow pattern accordingly the number of plate in Heating, Cooling section changes.

Equivalent diameter of a plate,

$$
D_{e q}=\frac{4 \times W \times G}{2(W+G)} \quad \text { As, } \mathrm{W}>>\mathrm{G}, D_{e q}=2 G
$$

Flow pattern of milk $=m \times n$

Flow pattern of water $=k \times f$

Flow area for water, $A_{w}=f \times(W \times G)$

Flow area for milk, $A_{m}=W \times G$

Velocity of milk flow, $v_{m}=V_{m} / A_{m}$ 
Velocity of water flow, $v_{w=} V_{w} / A_{w}$

$$
\begin{aligned}
& \text { So, }\left(N_{R e}\right)_{m}=\frac{\rho_{m} v_{m} D_{e q}}{\mu_{m}} \\
& \left(N_{P r}\right)_{m}=\frac{\mu_{m} C_{p m}}{k_{m}} \\
& \left(N_{N u}\right)_{m}=\frac{D_{e q} h_{m}}{k_{m}}=0.28 N_{R e}^{0.65} N_{P r}^{0.4} \\
& \left(N_{R e}\right)_{w}=\frac{\rho_{w} v_{w} D_{e q}}{\mu_{w}} \\
& \left(N_{P r}\right)_{w}=\frac{\mu_{w} C_{p w}}{k_{w}} \\
& \left(N_{N u}\right)_{w}=\frac{D_{e q} h_{w}}{k_{w}}=0.28 N_{R e}^{0.65} N_{P r}^{0.4} \\
& U=\frac{1}{\frac{1}{h_{w}}+\frac{\Delta x}{k_{s s}}+\frac{1}{h_{m}}} \\
& Q=\rho_{m} v_{m} A_{m} C_{p m} \Delta T_{m}=\rho_{w} v_{w} A_{w} C_{p w} \Delta T_{w} \\
& A_{p}=(L \times W)+0.015 \\
& A=A_{p} \times n
\end{aligned}
$$

So, number of plate including 2 end plates,

$n_{\text {act }}=n+2$

\section{Regression used for milk and water properties:}

3.1. Regression for milk properties:

$\mathrm{T}$ in ${ }^{\circ} \mathrm{C}$

$k_{m}=0.539911+0.00133 T$

$\rho_{m}=1033.7-0.2308 T-0.00246 T^{2}$

$\mu_{m}=(-0.00445 T+0.947) \times 10^{-3}$

$C_{p m}=(1.68 T+3864.2)$

Equivalent diameter of a plate,

$$
D_{e q}=\frac{4 \times W \times G}{2(W+G)} \quad \text { As, } \mathrm{W}>>\mathrm{G}, D_{e q}=2 G
$$

Flow pattern of milk $=m \times n$

Flow pattern of water $=k \times f$

Flow area for water, $A_{w}=f \times(W \times G)$

3.2. Regressionfor steam/condensate properties: For temperature within 345K-530K, $\mathrm{T}$ in Kelvin $k_{w}=-0.0007 T+1.003$

$\rho_{w}=-0.8392 T+1270.2$

$\mu_{w}=0.0072 e^{-0.009 T}$

$C_{p w}=1000(0.0021 T+3.4571)$

For temperature within 273K-310K, $\mathrm{T}$ in $\mathrm{C}$

$k_{w}=0.0015 T+0.5709$

$\rho_{w}=-0.0065 T^{2}+0.0581 T+999.98$

$\mu_{w}=0.0000005 T^{2}-0.00005 T+0.0017$

$$
C_{p w}=1000\left(0.00004 T^{2}-0.0025 T+4.2153\right)
$$

\section{Development of Interface:}

Using Visual Basic 2012, at first make the Form1(Fig:1). It includes 8 command buttons for different options that can be taken by the user and label lines also.

By clicking the button user can access the desired design environments e.g. Triple Tube HE (Straight Type) or Plate Type.

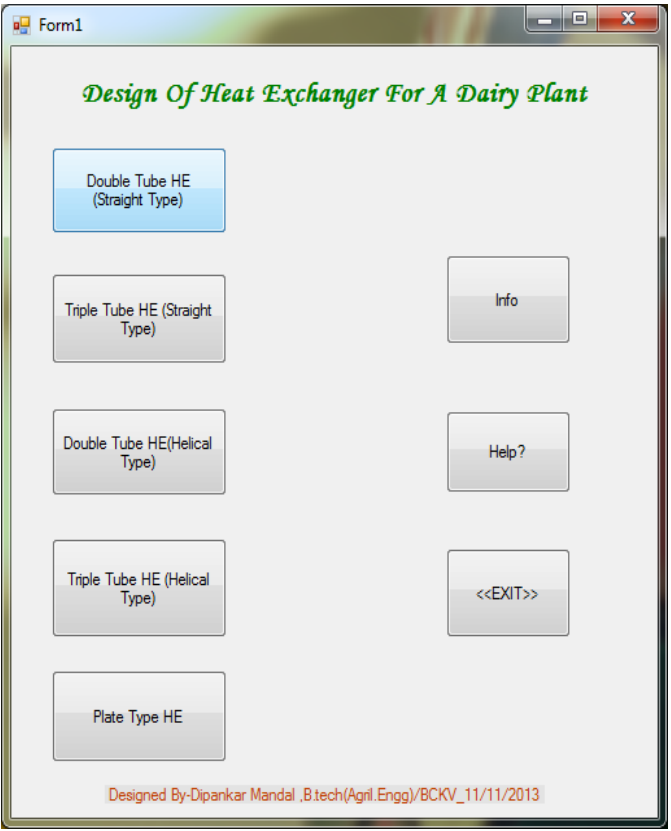

Fig-1:Form1

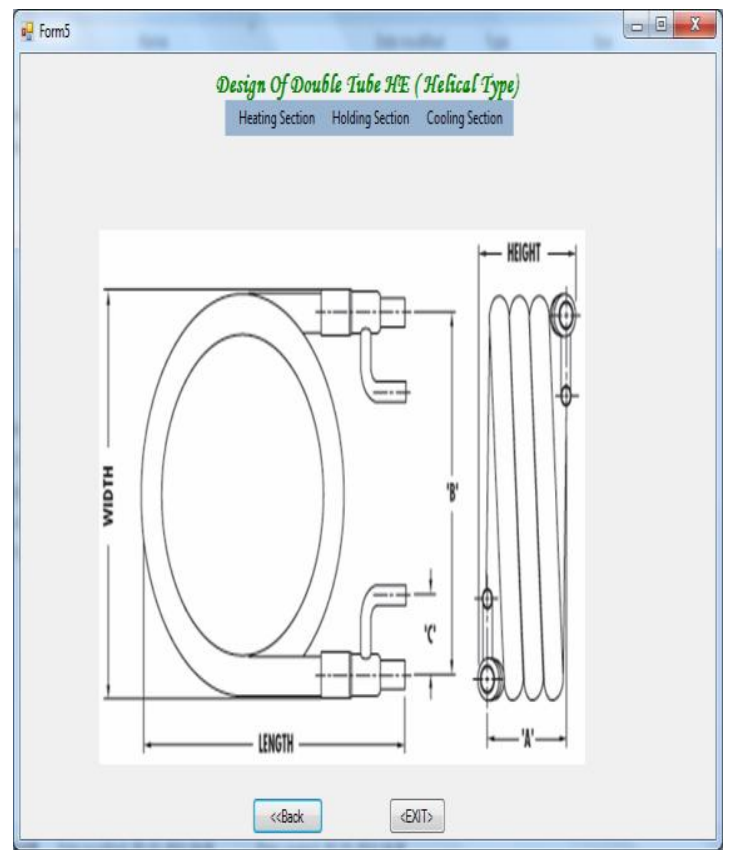

Fig-2: Form5

In each command button includes its linked environment form. Each form has 3 sections at theMenu-strip bar-Heating Section, Holding Section and Cooling Section. (Form5).Fig:2.

If user wants to design heating section then click to the option on menu-strip bar and it opens a interactive window and asks user to give inputs as he 
desired from case study of the projected plan of the Dairy Plant.

Then push the CALCULATE button and the designed parameter will show in the output boxes provided in it, Form6.(Fig:3)

In that way a user can easily design the plant sections by the software.

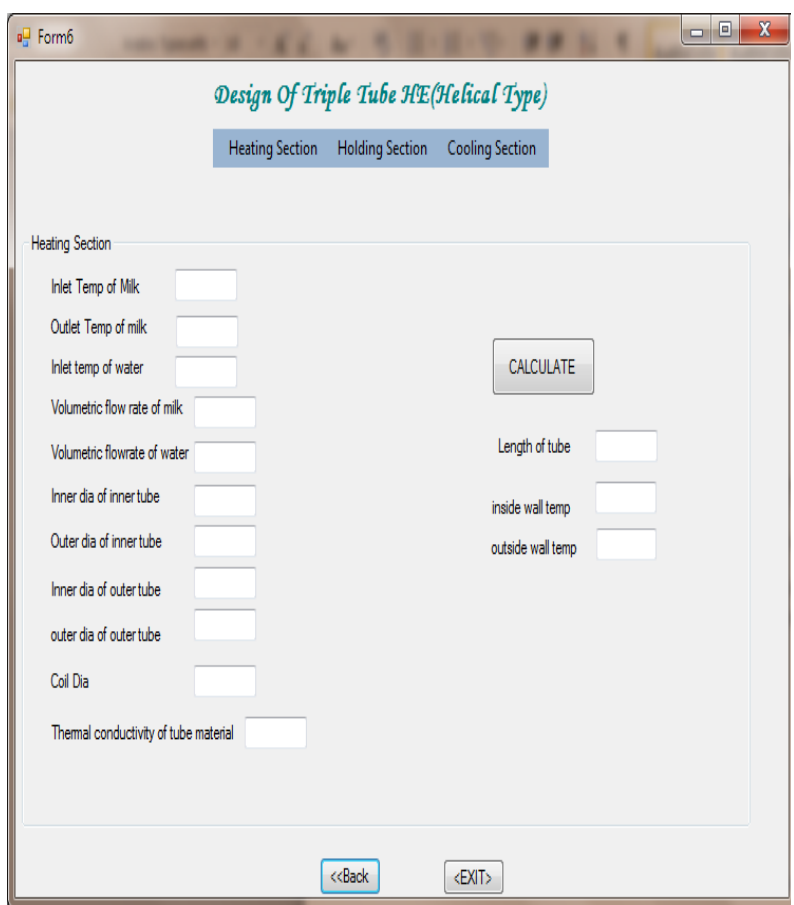

Fig-3: Form6

V. Programs in Visual Basic 2012:

This program is based on the visual basic structures. The program starts with initialization of two variables $T_{\text {ilwall }}, T_{o 2 \text { wall }}$ and the assumed values go through some equations which ultimately gives a new value of $T_{\text {ilwall }}, T_{o 2 \text { wall }}$.Now in condition box it checks the values are same as the assumed value or not. If it is same then it outputs the value of the tube length. If not, it runs again through the loop. The basic flow chart of the program is given below:

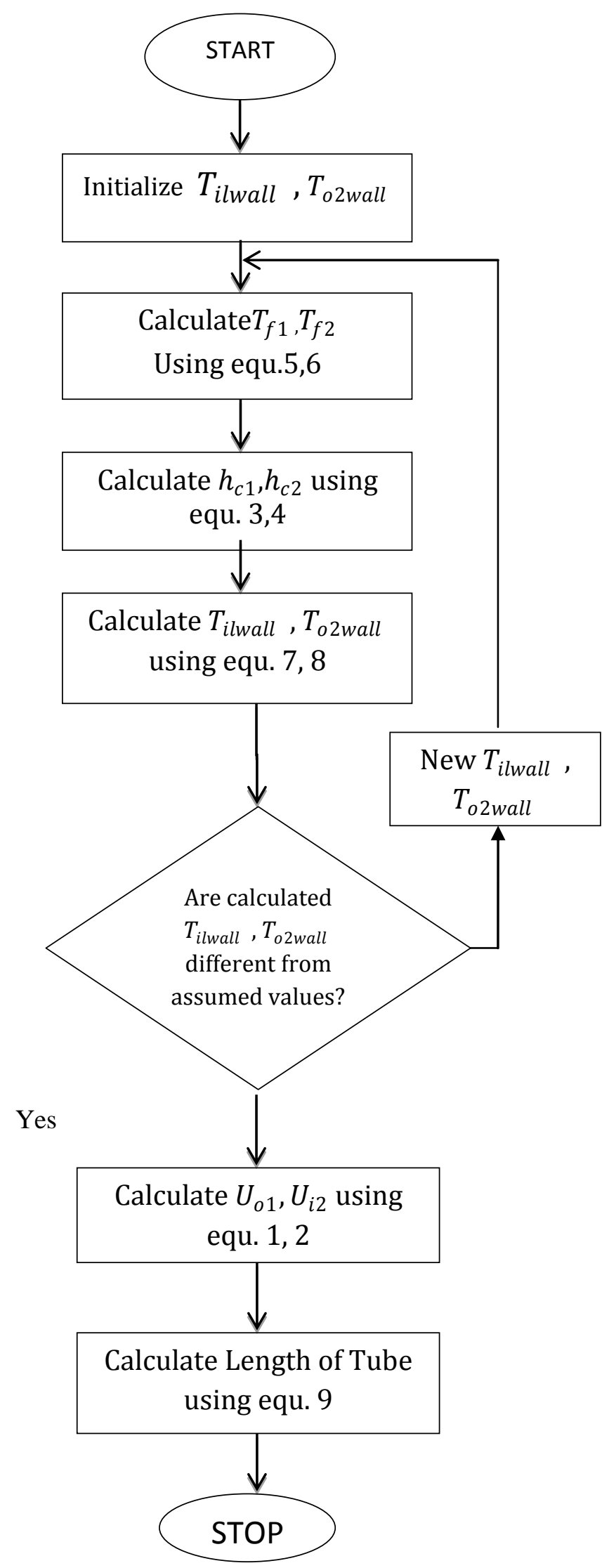




\section{Results and Discussion}

We have gone for a run of the program using some standard data and check the computed results given by the software with theoretically calculated value.

Set of Data:

For Helical Type triple tube Heating Section Design:: Inner diameter of the innermost tube $=0.006 \mathrm{~m}$ Outer diameter of the innermost tube $=0.0085 \mathrm{~m}$ Inner diameter of middle tube $=0.0127 \mathrm{~m}$

Outer diameter of the middle tube $=0.015 \mathrm{~m}$

Diameter of coil $=0.3 \mathrm{~m}$

Temperature of steam $=160 \square \mathrm{C}$

Inlet Temperature of Milk $=90 \square \mathrm{C}$

Outlet temperature of Milk=150 $\square \mathrm{C}$

Flow rate of milk=150 lit/h

Flow rate of water $=600 \mathrm{lit} / \mathrm{h}$

Calculated: Theoretically calculated value of length of tube $=1.45 \mathrm{~m}$

And Inside wall temperature $=139.1 \square \mathrm{C}$ and outside wall temperature $=143.52 \square \mathrm{C}$.

And output value using the software is given in following window.(Fig:4)

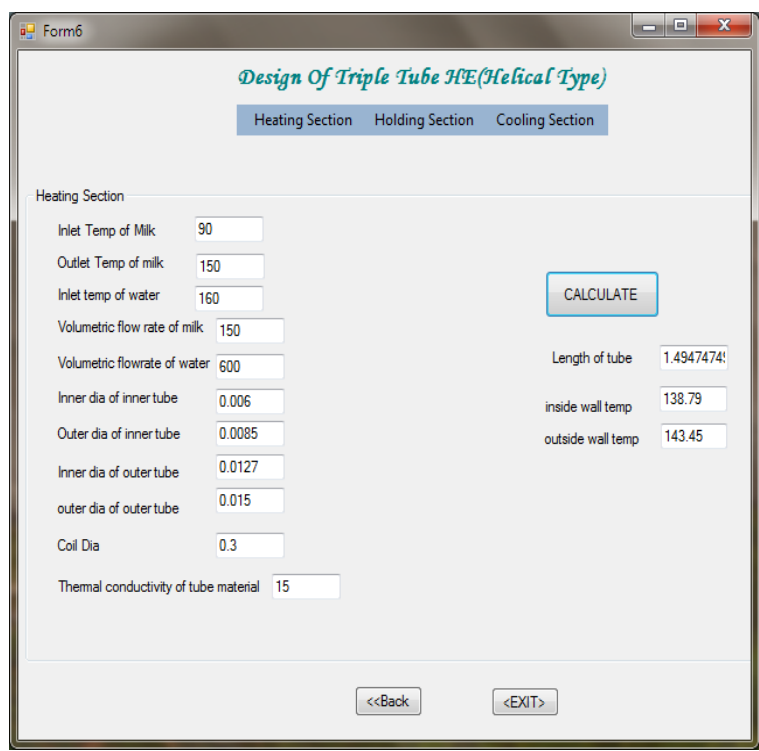

\section{Fig-4: Form6 output Window}

Now, for evaluation of different types of heat exchanger we test the data for different inlet temperatures of milk and water inlet temperatures. The result sheet is given in TABLE-1 and TABLE-2.

And a performance evaluation plot is shown in

Fig:5 (Length of the tubes in Log Scale vs . water inlet temperature $\square$ C).It shows that high the inlet temperature - less the tube length. For a particular temperature, less tube length occurs from Double Straight tube to Triple Helical tube.
Table-1:

\begin{tabular}{|c|c|c|c|c|c|c|}
\hline $\begin{array}{c}\text { Milk } \\
\text { inlet } \\
\text { Temp. } \\
\text { C }\end{array}$ & $\mathbf{9 0}$ & $\mathbf{1 0 0}$ & $\mathbf{1 1 0}$ & $\mathbf{9 0}$ & $\mathbf{1 0 0}$ & $\mathbf{1 1 0}$ \\
\hline $\begin{array}{c}\text { Water } \\
\text { Inlet } \\
\text { Temp. } \\
\text { C }\end{array}$ & $\begin{array}{c}\text { Double } \\
\text { Straight }\end{array}$ & $\mathbf{D S}$ & $\mathbf{D S}$ & $\begin{array}{c}\text { Double } \\
\text { Helical }\end{array}$ & $\mathbf{D H}$ & $\mathbf{D H}$ \\
\hline 160 & 7.7 & 7 & 6.2 & 7.7 & 6.9 & 6 \\
\hline 165 & 6.3 & 5.7 & 4.9 & 6.3 & 5.6 & 4.8 \\
\hline 170 & 5.4 & 4.8 & 4.1 & 5.3 & 4.7 & 4 \\
\hline 175 & 4.7 & 4.1 & 3.5 & 4.6 & 4 & 3.4 \\
\hline 180 & 4.2 & 3.7 & 3.1 & 4.1 & 3.6 & 3 \\
\hline 185 & 3.8 & 3.3 & 2.8 & 3.7 & 3.2 & 2.7 \\
\hline 190 & 3.5 & 3 & 2.5 & 3.4 & 2.9 & 2.4 \\
\hline 195 & 3.2 & 2.8 & 2.3 & 3.1 & 2.7 & 2.2 \\
\hline 200 & 3 & 2.6 & 2.1 & 2.9 & 2.5 & 2 \\
\hline 205 & 2.8 & 2.4 & 2 & 2.7 & 2.3 & 1.9 \\
\hline 210 & 2.6 & 2.2 & 1.8 & 2.5 & 2.1 & 1.7 \\
\hline 215 & 2.4 & 2.1 & 1.7 & 2.3 & 2 & 1.6 \\
\hline 220 & 2.3 & 2 & 1.6 & 2.2 & 1.9 & 1.5 \\
\hline 225 & 2.2 & 1.9 & 1.5 & 2.1 & 1.8 & 1.4 \\
\hline 230 & 2.1 & 1.8 & 1.4 & 2 & 1.7 & 1.4 \\
\hline 235 & 2 & 1.7 & 1.4 & 1.9 & 1.6 & 1.3 \\
\hline 240 & 1.9 & 1.6 & 1.3 & 1.8 & 1.5 & 1.2 \\
\hline 245 & 1.8 & 1.5 & 1.2 & 1.7 & 1.4 & 1.2 \\
\hline 250 & 1.7 & 1.5 & 1.2 & 1.6 & 1.4 & 1.1 \\
\hline 255 & 1.7 & 1.4 & 1.1 & 1.6 & 1.3 & 1.1 \\
\hline 260 & 1.6 & 1.3 & 1.1 & 1.5 & 1.3 & 1 \\
\hline 265 & 1.5 & 1.3 & 1.1 & 1.4 & 1.2 & 1 \\
\hline 270 & 1.5 & 1.2 & 1 & 1.4 & 1.2 & 0.9 \\
\hline
\end{tabular}


Table-2:

\begin{tabular}{|c|c|c|c|c|c|c|}
\hline $\begin{array}{c}\text { Milk } \\
\text { inlet } \\
\text { Temp. } \\
\text { C }\end{array}$ & $\mathbf{9 0}$ & $\mathbf{1 0 0}$ & $\mathbf{1 1 0}$ & $\mathbf{9 0}$ & $\mathbf{1 0 0}$ & $\mathbf{1 1 0}$ \\
\hline $\begin{array}{c}\text { Water } \\
\text { Inlet } \\
\text { Temp. } \\
\mathbf{C}\end{array}$ & $\begin{array}{c}\text { Triple } \\
\text { Straight }\end{array}$ & $\mathbf{T S}$ & $\mathbf{T S}$ & $\begin{array}{c}\text { Triple } \\
\text { Helical }\end{array}$ & $\mathbf{T H}$ & $\mathbf{T H}$ \\
\hline 160 & 1.7 & 1.5 & 1.3 & 1.5 & 1.3 & 1.2 \\
\hline 165 & 1.4 & 1.2 & 1 & 1.2 & 1.1 & 0.9 \\
\hline 170 & 1.2 & 1 & 0.9 & 1.1 & 0.9 & 0.8 \\
\hline 175 & 1 & 0.9 & 0.7 & 0.9 & 0.8 & 0.7 \\
\hline 180 & 0.9 & 0.8 & 0.7 & 0.8 & 0.7 & 0.6 \\
\hline 185 & 0.8 & 0.7 & 0.6 & 0.8 & 0.7 & 0.5 \\
\hline 190 & 0.8 & 0.7 & 0.5 & 0.7 & 0.6 & 0.5 \\
\hline 195 & 0.7 & 0.6 & 0.5 & 0.6 & 0.5 & 0.5 \\
\hline 200 & 0.7 & 0.6 & 0.5 & 0.6 & 0.5 & 0.4 \\
\hline
\end{tabular}

\begin{tabular}{|l|l|l|l|l|l|l|}
205 & 0.6 & 0.5 & 0.4 & 0.6 & 0.5 & 0.4 \\
\hline 210 & 0.6 & 0.5 & 0.4 & 0.5 & 0.4 & 0.4 \\
\hline 215 & 0.5 & 0.5 & 0.4 & 0.5 & 0.4 & 0.3 \\
\hline 220 & 0.5 & 0.4 & 0.4 & 0.5 & 0.4 & 0.3 \\
\hline 225 & 0.5 & 0.4 & 0.3 & 0.4 & 0.4 & 0.3 \\
\hline 230 & 0.5 & 0.4 & 0.3 & 0.4 & 0.4 & 0.3 \\
\hline 235 & 0.4 & 0.4 & 0.3 & 0.4 & 0.3 & 0.3 \\
\hline 240 & 0.4 & 0.4 & 0.3 & 0.4 & 0.3 & 0.3 \\
\hline 245 & 0.4 & 0.3 & 0.3 & 0.4 & 0.3 & 0.3 \\
\hline 250 & 0.4 & 0.3 & 0.3 & 0.4 & 0.3 & 0.2 \\
\hline 255 & 0.4 & 0.3 & 0.3 & 0.3 & 0.3 & 0.2 \\
\hline 260 & 0.4 & 0.3 & 0.2 & 0.3 & 0.3 & 0.2 \\
\hline 265 & 0.4 & 0.3 & 0.2 & 0.3 & 0.3 & 0.2 \\
\hline 270 & 0.3 & 0.3 & 0.2 & 0.3 & 0.3 & 0.2 \\
\hline
\end{tabular}

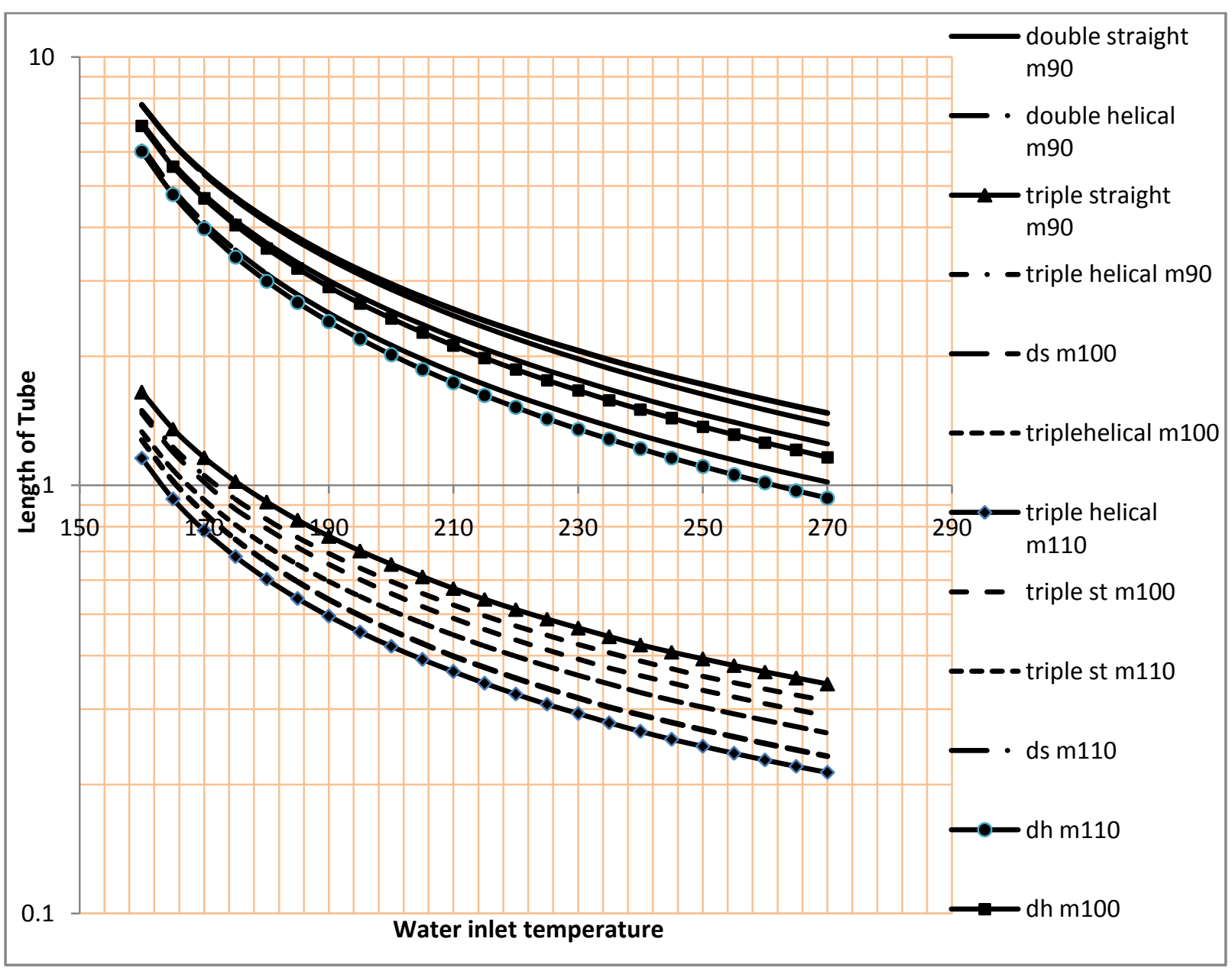

Fig-5: Performance evaluation of different types of heat exchangers at different milk inlet temperature 


\section{Conclusion}

Once a user is convenient with the software, it is very less time consuming for trial calculation for design parameters in the environment. And it is very user friendly software for plant design.

\section{REFERENCE:}

[1] Geankoplis,C.J., Transport process and separation Process Principles, $4^{\text {th }}$ ed. (New Delhi: Prentice-Hall,1997).

[2] Kern, D. Q.Process Heat Transfer(New York: McGraw-Hill, 1984)263-269.

[3] Toledo, R.T. Fundamentals of food process engineering, $3^{\text {rd }}$ ed. (Springer, 2007).

[4] Holman, J.P., Heat Transfer, $10^{\text {th }}$ ed. (McGraw-Hill, 2010)

[5] Sahoo, P.K., Datta, A.K.,Ansari.Md.I.A..Computer-aided design and performance evaluation of an indirect type helical tube ultra-high temperature (UHT) milk sterilizer, Journal of Food Engineering, 51,2002,13-19.

[6] Nema.P.K.,Datta,A.K., A computer based solution to check the drop in milk outlet temperature due to fouling in a tubular heat exchanger,Journal of Food Engineering, 71,2005,133-142.

[7] Timothy J. Rennie,Raghaban,V.G.S Experimental studies of a double-pipe helical heat exchanger,Experimental Thermal and Fluid Science, 29 ,2005, 919924.

[8] Bhavasar.J.J,Matawala V.K,Dixit.S. Design and experimental analysis of spiral tube heat exchanger,International Journal of Mechanical and Production Engineering, ISSN: 2320-2092, 1,2013,37-42.

[9] Rennie.T.J. Numerical and experimental studies of a double pipe helical heat exchanger, doctoral diss., Mc Gill University, 2004.

[10] Purandare, P.S., Lele.M.M.,Gupta.R, Parametric Analysis of Helical Coil Heat Exchanger,International Journal of Engineering Research \& Technology,1,2012,01-05. 